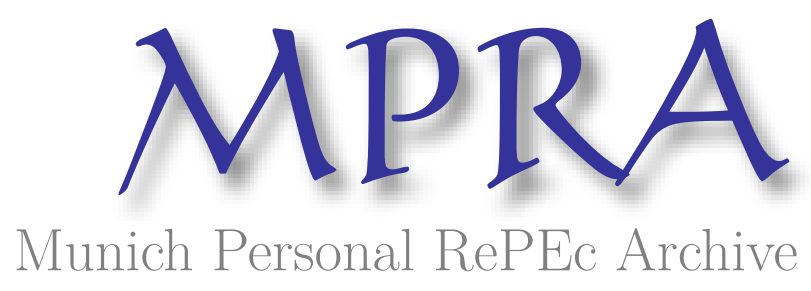

\title{
The Cultural Roots of Human Capital Accumulation
}

van Hoorn, Andre

2016

Online at https://mpra.ub.uni-muenchen.de/80007/

MPRA Paper No. 80007, posted 04 Jul 2017 13:26 UTC 


\title{
The Cultural Roots of Human Capital Accumulation
}

\begin{abstract}
While the accumulation of human capital is widely recognized as a key driver of economic development, what drives cross-country differences in human capital accumulation remains little understood. I use an epidemiological approach involving migrants to test for a possible cultural gradient in individuals' propensity towards human capital accumulation. However, advancing on traditional macro-focused epidemiological culture research, I also explore a specific micro-level channel through which country-of-origin culture affects human capital accumulation involving culture's effect on individuals' dispositions. Results confirm a cultural gradient in the propensity towards human capital accumulation. Moreover, part of the effect of culture on migrants' propensity towards human capital accumulation runs through migrants' personal dispositions. Finally, culture's effect on human capital accumulation traces back to cultural differences in emphasis on intellectual autonomy and future orientation. I conclude that understanding countries' differential development experiences requires detailed study of the various micro channels through which culture can have macroeconomic consequences.
\end{abstract}

JEL codes: I20, O11, Z10

Keywords: Culture; skill accumulation; epidemiological approach; intellectual autonomy; microfoundations 
All of the East Asian miracle economies have become [...] increasingly well-educated. [...] These facts—or at least some of them-must figure in any explanation of the growth miracles, but they are additions to the list of events we want to explain, not themselves explanations.

- Robert Lucas, 1993, p.252

\section{Introduction}

Human capital accumulation is an important source of economic growth and development (Barro, 1991; Erosa et al., 2010; Gennaioli et al., 2013; Mankiw et al., 1992; Manuelli and Seshadri, 2014). However, in explaining countries' growth experience, the accumulation of human capital is a proximate factor that itself requires explaining (Lucas, 1993). In fact, some authors find that capital accumulation or education are best seen as manifestations of growth rather than as causal factors; "they are growth" (North and Thomas, 1973, p.2).

In an influential paper, Acemoglu et al. (2001) propose that the nature of the formal institutions in a country, specifically whether institutions are extractive or inclusive, is critical for development. They test this argument using data on settler mortality, finding that European colonizers designed institutions aimed at extracting value rather than creating value in environments in which their chances of survival were smaller. Other work is more critical of the role of formal institutions, suggesting that human capital is a more basic source of growth than formal institutions are (Glaeser et al., 2004). Particularly, the argument is that European colonizers did not bring with them institutions as much as they brought human capital—and more of this human capital settled permanently in places more hospitable to Europeans, i.e., in places with lower settler mortality. Still other work identifies informal institutions such as culture and certain societal norms as fundamental drivers of economic development (see Nunn, 2012, 
Roland, 2015, and Spolaore and Wacziarg, 2013 for surveys; see, also, Fukuyama, 1995 and Landes, 1998). Meanwhile, the challenge put forth by Lucas (1993) and North and Thomas (1973) of studying human capital as an explanandum rather than an explanans remains largely unaddressed.

This paper takes up this challenge, extending the culture-development literature to study the role of culture as a deep factor underlying individuals' propensity towards human capital accumulation. A straightforward definition of culture is as values, beliefs and norms that are shared by members of a group and are transmitted fairly unchanged from generation to generation (Guiso et al., 2006; Javidan et al., 2006). Standard human capital theory (Becker, 1964; Mincer, 1958) finds that the expected rate of return on investment and people's preferences (particularly their level of impatience) together determine how much human capital an individual accumulates. Empirical work confirms this insight, identifying both individuals' level of impatience (Cadena and Keys, 2015) and their life expectancy (Oster et al., 2013)—a proxy for return on investment—as important factors driving individual differences in human capital. Cross-country differences in human capital have similarly been related to differences in life expectancy but also to differences in access to public education (Cordoba and Ripoll, 2013). Studies of the economic consequences of culture commonly focus on the effect of cooperative norms or social trust on the level of per-capita GDP and a variety of other societal structures and outcomes (Algan and Cahuc, 2010; Knack and Keefer, 1997). However, there is also a growing number of studies that relates specific dimensions of national culture to different economic phenomena (Bloom et al., 2012; Davis and Williamson, 2016; Davis and Abdurazokzoda, 2016; Gorodnichenko and Roland, 2011, 2016; Klasing, 2013; Van Hoorn, 2014). Finally, there is some work at the intersection of cross-country education and culture research. Hofstede (2001) 
and Minkov (2007), for instance, find that cultural future orientation affects academic achievement (see, also, Hofstede and Minkov, 2010). Related research finds that dimensions of national culture predict differences in classroom behavior and learning practices (e.g., Cortazzi and Jin, 2013). My concern is not with such educational phenomena, however, but with culture as a factor explaining the accumulation of human capital (cf. Lucas, 1993). The main hypothesis that I test in this paper is that national culture affects individuals' propensity towards human capital accumulation.

To test this hypothesis I follow earlier culture research (e.g., Atkin, 2016; Fernández and Fogli, 2006) and apply an epidemiological approach involving data on migrants from different countries of origin that are at present living in various destination countries. Using data that combine different economic, institutional and cultural environments, it is possible to distil a preference-based effect of cultural background on individuals' propensity towards human capital accumulation that is unbiased by economic and other institutional conditions that might correlate with culture and cause biases. Underlying the epidemiological approach is the idea that culture continues to have an effect on migrants' preferences and behavior because culture is persistent, as per the large literature on cultural inertia and intergenerational transmission of values (e.g., Bisin and Verdier, 2001; Grosfeld and Zhuravskaya, 2015; Voigtländer and Voth, 2012). Importantly, however, I also expand on traditional macro-focused epidemiological culture research by considering a micro-level channel through which culture affects individuals' propensity towards human capital accumulation. Whereas broad-level correlations between country-of-origin culture and economic behavior in the destination country are suggestive of a cultural explanation for cross-country economic differences, deeper understanding of culture's economic consequences requires taking a combined micro/macro approach and analyzing how 
exactly culture may go on to affect economies in the aggregate. The specific micro channel that I consider in this paper is that culture affects migrants' propensity towards human capital accumulation partly through culture's effect on these individuals' personal dispositions. Finally, I incorporate insights from cross-cultural research identifying different dimensions of national culture and test two hypotheses concerning the effect of cultural differences in intellectual autonomy and future orientation on human capital accumulation.

Results for a sample of about 8,500 migrants reveal a significant effect of country-of-origin culture on individuals' propensity towards human capital accumulation. The same finding holds when considering the countries of origin of individuals' parents instead of current migrants. Moreover, the empirical evidence supports the idea that the effect of country-of-origin culture on human capital accumulation is partly mediated by individuals' dispositions. Finally, I find that cultural differences in emphasis on intellectual autonomy and future orientation are important for understanding differences in the accumulation of human capital across countries. These results are robust to a variety of checks, including adding controls for typical outcomes associated with human capital accumulation such as personal income and years of education. Hence, the paper finds robust evidence for national culture playing a role in cross-country differences in human capital accumulation, confirming the gist of Lucas' (1993) plea to consider education as a proximate rather than an ultimate cause of economic development.

This paper makes several contributions. Most obviously, the paper adds a significant explanatory factor to the literature seeking to understand countries' differential experiences in accumulating human capital. More generally, however, the paper is able to provide some microeconomic underpinning for the role of culture in accounting for economic differences between countries. Studies of the idea that culture can have critical economic consequences have 
a long history (Banfield, 1958; Weber, 1904/5). Empirical culture research typically examines aggregate-level relationships, however, thus neglecting the microeconomic foundations for culture's macroeconomic impact. The present paper, then, could provide some guidance on how to incorporate a mechanism for culture's macroeconomic consequences that is grounded in the personal dispositions of individuals. Overall, the paper draws attention to the need for more work that takes a combined micro/macro approach to study culture as a factor shaping economic outcomes.

\section{Background and empirical approach}

\subsection{Culture, preferences, and the accumulation of human capital}

In line with classic human capital theory (Becker, 1964; Mincer, 1958), I expect that culture plays a role in the accumulation of human capital because culture affects people's preferences (Guiso et al., 2006). Culture refers, among others, to certain value dispositions shared by members of a group (Javidan et al., 2006; Schwartz, 2006). Values, in turn, are akin to preferences and can be defined as concepts that pertain to desirable outcomes and provide nonsituation specific guidance to individuals in their selection and evaluation of alternative courses of action (Schwartz, 1992). As a group-level construct, culture refers to a general inclination among members of the group to have certain value dispositions or beliefs and to follow certain norms (Hofstede, 2001). Culture therefore is not deterministic but speaks to individuals' dispositions and affects the incidence of certain behaviors among the members of a particular cultural group, often a country, including their engagement in human capital accumulation.

Exploring the idea of culture affecting preferences, earlier work has found, for instance, that average fertility rates and labor force participation of women in the country of origin correlate 
with fertility rates and labor force participation of women that have migrated to the U.S. (Fernández and Fogli, 2006). Using the same approach, Atkin (2016) finds that state-of-origin food preferences correlate with food preferences and, ultimately, the caloric uptake of interstate migrants in India. For human capital accumulation, I similarly hypothesize a strong relationship between the average propensity towards human capital accumulation in the country of origin and migrants' engagement in the accumulation of human capital. Moreover, following the connection between culture and individuals' preferences (Guiso et al., 2006), I expect that a genuine effect of national culture on human capital accumulation involves a micro-level channel in which individuals' dispositions act as a mediator. That is, part of the effect of culture on individuals' engagement in human capital accumulation occurs because culture affects personal dispositions.

A further expectation is that it is possible to unpack the generic effect of culture on individuals' behavior that is central to epidemiological culture research and identify specific dimensions of national culture (Maseland and Van Hoorn, 2016; Roland, 2015) that affect migrants' propensity towards human capital accumulation. Instead of using averaged country-oforigin behavior, which is a rather thin construct, we can draw on quantitative frameworks of national culture developed by cross-cultural researchers to explain differences in the propensity towards human capital accumulation. These frameworks measure cultural differences between countries on specific sets of dimensions that have clear theoretical definitions. Out of the available frameworks and dimensions of national culture, I expect the intellectual autonomy dimension from the framework by Shalom Schwartz (e.g., 1994, 2006) and the future orientation dimension from the GLOBE framework (House et al., 2004) to be particularly relevant for understanding variation in human capital accumulation. In contrast to earlier culture frameworks (particularly Hofstede, 1980, 2001), both the Schwartz framework and the GLOBE framework 
are based on a priori theorizing as to the specific dimensions on which countries' cultures are likely to differ, making them the most advanced frameworks of national culture currently available (Maseland and Van Hoorn, 2016).

Shalom Schwartz (e.g., 1994, 2006) identifies three opposing dimensions of national culture, including embeddedness versus autonomy. Embeddedness thereby refers to being a member of a group and sharing goals within a group. Autonomy on the other hand is about encouragement of individuals to pursue their own interests and experiences. A specific component of the autonomy dimension is intellectual autonomy, which is about encouragement for individuals to pursue their own ideas and intellectual directions (Schwartz, 2006, p.140). The expected effect of greater emphasis on intellectual autonomy therefore is to strengthen individuals' preference for having knowledge about the world around them and for learning new things. Hence, the specific hypothesis that I test is that migrants from countries with more cultural emphasis on intellectual autonomy have a stronger tendency to accumulate human capital.

Future orientation is defined as "the degree to which individuals in organizations or societies engage in future-oriented behaviors such as planning, investing in the future, and delaying gratification" (House et al., 1999). ${ }^{1}$ A further explication of future orientation is that it concerns the extent to which members of a society "focus on investment in their future" as well as "look far into the future for assessing the effects of their current actions" (Ashkanasy et al., 2004,

${ }^{1}$ Future orientation can also be referred to as long-term orientation, which is the term used by Hofstede (2001). For this paper, I consider future orientation because Hofstede's $(1980,2001)$ culture framework has been heavily criticized for not actually measuring culture, notably because country scores on his measures are highly dependent on reigning circumstances (Maseland and Van Hoorn, 2009, 2010; Taras et al., 2010; see, also, Roland, 2015). 
p.285). Accordingly, I expect that migrants from countries that are more strongly future-oriented are more inclined to see human capital accumulation as an attractive investment opportunity and are more willing to incur short-term costs in order to engage in the accumulation of human capital. Hence, the specific hypothesis that I test is that migrants from countries that are more strongly future-oriented have a stronger tendency to accumulate human capital.

Figure 1 presents an overview of the variables analyzed in this paper and their expected relationships (see, also, Eq. 1 below).

$<<$ Insert Figure 1 about here >>

\subsection{Identifying the effect of national culture on human capital accumulation}

The basis of my approach to empirically analyzing the role of culture in human capital accumulation is the cross-country epidemiological approach used by Fernández and Fogli (2006), among others. By using measures of average behavioral propensities in the region of origin, these studies have advanced on earlier culture research that considered fixed region-oforigin effects in migrant outcomes (e.g., Carroll et al., 1994). An important advancement provided by the present paper is that I not only assess the relationship between country-of-origin average behavioral propensities and migrant behavior in the destination country, but also consider the mediating effect of individuals' dispositions that act as a channel linking grouplevel culture to individual behavior.

The baseline model that I estimate reads as follows:

$$
\mathrm{A}_{\text {iod }}=\beta_{0}+\beta_{1} \mathrm{C}_{\mathrm{io}}+\beta_{2} \mathrm{X}_{\mathrm{i}}+\beta_{3} \mathrm{Y}_{\mathrm{io}}+\beta_{4} \mathrm{Z}_{\text {iod }}+\mathrm{D}_{\mathrm{id}}+\varepsilon_{\text {iod }} .
$$


$\mathrm{A}_{\mathrm{iod}}$ thereby refers to human capital accumulation (1=yes) by individual $\mathrm{i}$ from country of origin o and currently living in destination country $\mathrm{d}$. For testing the hypothesis that national culture affects individuals' propensity towards human capital accumulation, the independent variable of interest is variable $C_{i o}$, which refers to the culture of individual i's country of origin. Other variables are included to control for potential confounders at the level of the individual $\left(\mathrm{X}_{\mathrm{i}}\right)$, the country of origin $\left(\mathrm{Y}_{\mathrm{io}}\right)$, and the origin-destination dyad $\left(\mathrm{Z}_{\mathrm{iod}}\right)$. Meanwhile, $\mathrm{D}_{\mathrm{id}}$ refers to a set of destination country dummies that controls for differences in migrants' accumulation of human capital that are due to specific features of their destination country.

To flesh out a potential channel that links country-of-origin culture to human capital accumulation, I extend Eq. 1 to include a mediator variable referring to certain dispositions that individual migrants may have. Similarly, to consider specific dimensions of national culture (Roland, 2015) that might affect the propensity towards human capital accumulation, I use alternative operationalizations of the culture measure $C_{\mathrm{io}}$. I estimate Eq. 1 using logit models. However, I obtain similar results when using probit models instead (results available on request). Finally, as my sample involves migrants from different countries of origin, I correct my standard errors for clustering at the country-of-origin level. In this case, I obtain similar results (available on request) if I use a multilevel approach and simultaneously estimate joint models for individual-level variation and for variation that is between countries of origin.

\section{Data}

\subsection{Main source and sample}

The main source of data used for my analysis is the bi-annual European Social Survey or ESS. I 
use the cumulative data file, which covers six waves of data collected in 2002, 2004, 2006, 2008, 2010 and 2012 (European Social Survey, 2014). Following earlier analyses of migrants using ESS data (e.g., Bisin et al., 2011), I identify migrants in this data set using respondents' answers to a set of questionnaire items. First, I distinguish between migrants and natives depending on the answer to the item asking respondents whether they are born in the country. Next, I use the follow-up item asking respondents in which country they are born to identify individuals' country of origin. Given the nature of these questionnaire items, this procedure classifies a small group of individuals as migrants even though they are actually natives. This group comprises individuals that have been born in a foreign country, even though their parents are natives. This may happen, for instance, when someone was born while his/her parents were on holiday abroad. To ensure that my sample comprises only genuine migrants, I exclude this group of individuals, using the ESS items that ask respondents about the country of birth of their mother or father. That is, I exclude respondents that are living in the country of birth of their parents even though these respondents themselves are born in a foreign country.

After exclusion of respondents with missing data and depending on specific variables considered, I end up with a sample of about 8,500 migrants. Table A.1 in the appendix presents an overview of the origin countries in the sample. The destination countries in the sample, 32 in total, are: Austria, Belgium, Bulgaria, Switzerland, Cyprus, Czech Republic, Germany, Denmark, Estonia, Spain, Finland, France, United Kingdom, Greece, Croatia, Hungary, Ireland, Israel, Iceland, Italy, Lithuania, Luxembourg, Netherlands, Norway, Poland, Portugal, Russia, Sweden, Slovenia, Slovakia, Turkey, and Ukraine.

As an alternative to the above migrant sample, I also consider a sample of individuals for which country of origin is measured as the country of origin of their parents instead of their own 
country of birth. I use this sample of second-generation migrants as a way of further limiting the potential for reverse causality in the relationship between country-of-origin culture and destination-country behavior. The approach to identifying individuals belonging to this sample is to select respondents that are born in the destination country but whose parents have been born elsewhere. Similarly, I identify the country of origin for these individuals by their answer to the two items asking them about the country of birth of their mother and father. I thereby exclude individuals whose parents are not born in the same foreign country. The resulting sample comprises 2,933 migrants and covers 31 countries of origin (out of a possible 32 countries for which the ESS data set can provide a measure of country-of-origin propensity towards human capital accumulation). Table A.2 in the appendix presents descriptive statistics for this secondgeneration migrant sample.

\subsection{Dependent variable: Human capital accumulation}

I measure individuals' propensity towards human capital accumulation by their answer to the following survey item: "During the last twelve months, have you taken any course or attended any lecture or conference to improve your knowledge or skills for work?" This item has a dichotomous answer scale, capturing whether or not respondents have engaged in such human capital accumulation (1=yes). A major advantage of the measure of human capital accumulation provided by this item is that it refers to behavior and the actual act of accumulating human capital accumulation and not to a stock that has been accumulated in the past. Meanwhile, there is ample evidence to support the validity of the answers to this item, the item's comparatively simple nature notwithstanding. Specifically, answers to the item vary in expected ways with answers to other questionnaire items capturing related constructs (Table 1). Respondents in jobs 
that require learning new things, for instance, are much more likely to report having engaged in the accumulation of new knowledge and skills than respondents in jobs that do not require learning new things are. Similarly, younger people are substantially more prone to accumulate human capital than older people are, which is expected given how much time these two groups have left to earn a return on their human capital investments.

$<<$ Insert Tables 1 and 2 about here>>

At the same time, this measure has an obvious limitation, which is that it does not capture how many courses/lectures/conferences individuals have taken/attended in the last twelve months or the intensity or duration of these activities. Still, the evidence presented in Table 1 does show that this measure is able to capture important features of individuals' engagement in human capital accumulation. Table 2 presents descriptive statistics for the measure of human capital accumulation and selected other variables.

\subsection{Key independent variable: National culture}

Average behavioral propensity in the country of origin. My key independent variable concerns the culture of migrants' countries of origin. The main culture measure that I use is constructed by calculating the average behavioral tendency in the country of origin, which is standard in the literature (see, for example, Fernández and Fogli, 2006). Thus, drawing on the same ESS item as before, I calculate the percentage of respondents in the country of origin that indicate having attended one or more courses, lectures or conferences to improve their knowledge or skills for work in the last twelve months. Differences in the average propensity 
towards human capital accumulation are considerable, ranging from a low of about $7 \%$ in Turkey and Bulgaria to more than $52 \%$ in Iceland (Table A.1 in the appendix).

My use of an epidemiological approach is meant to facilitate analysis of the effect of individuals' cultural background on their behavior, independent of the economic, institutional and cultural environment in which these individuals currently find themselves. However, to be able to identify more clearly that the relationship between country-of-origin culture and human capital accumulation reflects a causal effect of culture, I also construct a measure of country-oforigin culture that precedes migrants' behavior in the destination country, thus limiting the potential for reverse causality. I do so by calculating country-of-origin propensity towards human capital accumulation for a sample of older individuals. Cultural values are a stable trait of individuals that gets formed in their pre-adult formative years (Hofstede, 2001; House et al., 2004; Schwartz, 2006). Hence, there is no plausible theoretical argument of how the behavior of contemporary migrants can affect the cultural values, beliefs or norms of older individuals in the country of origin. The specific cut-off year that I select is 1968. I thus calculate my alternative measure of country-of-origin propensity towards human capital accumulation using only data from individuals born in 1967 or earlier. As expected, the propensity towards human capital accumulation tends to be lower in this older cohort compared to the general population (cf. Table 1). To save space, I do not present country scores on this culture measure but these scores are available on request.

Intellectual autonomy and future orientation dimensions of national culture. To measure differences in cultural emphasis on intellectual autonomy, I follow the procedure outlined in Schwartz (2006) and operationalize the dimensions of his framework using survey items included in all waves of the ESS. The relevant items ask respondents how important it is for 
them to think new ideas and be creative and to understand different people, among others. Further details about these survey items and the procedure for measuring Schwartz's cultural value dimensions using these items are available on request. The specific measure of future orientation that I use is the measure of future orientation practices available from House et al. (2004), which is based on data collected between 1995 and 1998. Table A.1 presents scores on these two culture dimensions for the countries in the sample.

\subsection{Control variables}

Demographics and other standard control variables. To limit the potential for spurious results, in addition to my main independent variable, I consider a variety of (individual-level) control variables. Given that I use an epidemiological approach involving non-natives currently residing in a range of destination countries, in all models I control for destination-country fixed effects. Similarly, all models control for year/wave fixed effects.

Further standard control variables concern basic demographics (sex, age and age squared) and aspects of individuals' employment history and work. These latter variables are total hours worked, historical experience of unemployment, employment relation (employee, self-employed, or working for own/family business), size of establishment (e.g., under 10 employees, 10 to 24 employees, 500 or more employees, et cetera) and current employment status (e.g., in paid work, in education, unemployed and looking for job, unemployed and not looking for job, retired, et cetera).

A specific concern is that country-of-origin culture may affect the degree to which a migrant is integrated in the destination country, which, in turn, affects the opportunity to accumulate human capital. This would be an effect that is driven by country-of-origin culture but would not 
necessarily involve individuals' preferences, which is the effect of culture emphasized in the present paper. Hence, I control for various factors capturing the degree of migrants' acculturation into the destination country. These factors are time spent in the destination country (5 years or less, 6-10 years, 11-20 years, or more than 20 years), whether the migrant is a citizen of the destination country, and whether he/she speaks the destination-country language at home.

To complete my set of standard control variables, I consider two features of the specific origin country-destination country dyad to which an individual belongs, as this could also be a confounding influence. The two dyadic features that I control for are geographic distance between the origin and destination country and whether the origin and destination country share the same official language. While data for the individual-level control variables are all included in the ESS data set, data for these latter two variables come from the CEPII GeoDist database (Mayer and Zignago, 2011).

Additional control variables for robustness checks. To check the robustness of my baseline results, I also consider some additional control variables beyond the above-described set of standard controls. First, there remains a generic concern that country-of-origin culture proxies for unobserved traits other than an individual's preferences that also have an effect on human capital accumulation. Second, there is a concern that the culture measure proxies for other, non-cultural country-of-origin characteristics that would affect migrants' destination-country behavior, specifically their engagement in human capital accumulation.

To address the former concern, I consider three additional control variables that are likely to be affected by the kind of unobserved individual-level traits that could render my baseline results spurious. These three variables are the individual's years of education, his/her personal income and the ease with which (s)he can borrow money from credit suppliers if needed. To address the 
latter concern, I consider three variables that pertain more to (historical) conditions in migrants' origin countries. These three variables are the education level of an individual's father and mother respectively and the mean years of schooling in the country of origin, which captures the net effect of all the non-cultural features of a country of origin that affect the propensity towards human capital accumulation in this country.

To be sure, all six variables are best seen as outcomes that are causally affected by the same factors that would causally affect migrants' engagement in human capital accumulation. The ease with which someone is able to borrow money, for instance, would be affected by the wealth that (s)he has accumulated, which, in turn, is connected to the tendency towards human capital accumulation. Hence, controlling for these variables increases the risk of making a Type II error in the analysis. Still, I consider these variables as a strict check of the robustness of the baseline results obtained using the set of standard control variables described above.

Years of education is measured as the answer to the ESS item asking respondents how many years of fulltime education they have completed. To measure personal income, I calculate a measure of rank income using respondents' answers to the ESS items that ask respondents to state the total net income of their household on a scale that runs from 1 to 12 (Waves 1-3, 20022006) or from 1 to 10 (Waves 4-6, 2008-2012). The advantage of using a measure of rank income is that it is comparable across countries and years, rendering a percentile score that indicates the percentage of respondents from the same country surveyed in the same year that had an income below that of the respondent. The ESS measures respondents' ability to borrow money using the following item: "If for some reason you were in serious financial difficulties and had to borrow money to make ends meet, how difficult or easy would that be?" Answers can range from 1 (Very difficult) to 5 (Very easy) and for simplicity I consider this measure as a 
cardinal measure. To be complete, a disadvantage of considering this last variable is that it has not been included in Wave 6 of the ESS, resulting in a comparatively small sample. However, I obtain similar results when I consider a larger sample and do not control for respondents' ability to borrow money (results available on request).

The education of an individual's mother and father is measured by two ESS items asking respondents about the level of education of their fathers and mothers (less than lower secondary education, lower secondary education completed, upper secondary education completed, postsecondary non-tertiary education completed, or tertiary education completed). Finally, I measure human capital in the origin country using data on mean years of schooling from the United Nations Development Programme (UNDP) Human Development Data (UNDP, 2016). Matching the start of the ESS data collection in 2002, I take the average of the mean years of schooling in 2000 and 2005. Results (available on request) are similar when using different averages.

\subsection{Individual-level variables to link national culture to human capital accumulation}

The final set of variables in my analysis concerns individual-level mediators that I use to explore a micro-level channel that links country-of-origin culture to human capital accumulation through individuals' personal dispositions. The main disposition that I consider concerns individuals' values, specifically their openness-to-change versus conservation values. Openness-to-change versus conservation values constitute one of the overarching value dimensions in the framework of universal human values also developed by Shalom Schwartz (e.g., Schwartz, 1992; Schwartz et al., 2001). Schwartz's framework has become the standard values framework in psychology and is designed to cover the whole spectrum of human motivations. Individuals that score higher on openness-to-change versus conservation values attach relatively much value to independent 
thought and new experiences and have less resistance to change. The expected direct effect of openness-to-change versus conservation values therefore is to increase the likelihood that an individual is engaged in the accumulation of human capital. The expected mediating effect is that part of culture's effect on human capital runs through individuals' openness-to-change versus conservation values. I measure openness-to-change versus conservation values using ESS value items designed by Schwartz. Schwartz et al. (2001) provide a detailed description of these items and the procedure for constructing the openness-to-change versus conservation value dimension. These details are also available on request.

As a second disposition, I consider individuals' occupation, specifically the average propensity towards human capital accumulation of all the individuals working in a particular occupation. The motivation for considering this specific mediator is that accumulating human capital may be an intrinsic feature of and more common in some occupations than in others so that part of individuals' preference for accumulating human capital is likely to be expressed in their chosen occupation. ${ }^{2}$ I measure occupation using standard four-digit ISCO codes recorded by the ESS. To classify occupations I calculate the percentage of all individuals working in a particular four-digit occupation that indicate having attended one or more courses, lectures or conferences to improve their knowledge or skills for work.

${ }^{2}$ Compared to values, which are strictly internal to individuals, occupation is more external to individuals, naturally raising the question of the degree to which individuals have control over their occupation. Even when individuals do not have full control when choosing a particular occupation, however, an individual's occupation seems highly informative about his/her personal dispositions (see, for example, Knafo and Sagiv, 2004, Stackman et al., 2006, and Van Hoorn, 2015 for evidence of systematic differences in the values of different occupations). 


\section{Results}

\subsection{Baseline results}

Table 3 presents results for the test of my main hypothesis that national culture affects human capital accumulation, using different specifications of the model depicted in Eq. 1. Results indicate a strong relationship between country-of-origin culture and migrants' engagement in human capital accumulation (Model 1). Hence, results support the existence of a cultural gradient in human capital accumulation. Variables that control for the impact of, for instance, acculturation (e.g., language spoken, citizenship) have the expected effect on the tendency to accumulate human capital (Model 2). In addition, the coefficient for country-of-origin culture decreases when these variables are included as additional control variables (Models 2 and 3). In general, however, culture appears an important factor accounting for differences in the propensity towards human capital accumulation. As a simple illustration, the effect of a one standard deviation increase in country-of-origin propensity towards human capital accumulation on migrants' human capital accumulation is comparable to the effect of speaking the destinationcountry language or having become a citizen of the destination country.

\footnotetext{
$<<$ Insert Table 3 about here $>>$
}

Meanwhile, it is important to realize that the found cultural gradient applies to an annual phenomenon, having taken/attended a course/lecture/conference during the last twelve months. Hence, the effect of culture on human capital accumulation found above—an odds ratio of 1.43 for a one standard deviation increase in country-of-origin propensity towards human capital 
accumulation (Model 3) - is repeated each year. Culture therefore appears to have the power to bring about wide disparities in countries' human capital stock, even over relatively short time spans.

\subsection{Robustness}

Addressing possible reverse causality. As a first check of the robustness of the above baseline results, I delve more deeply into the possibility of reverse causality. Applying an epidemiological approach, makes it rather implausible that the found relationship between culture and human capital accumulation reflects an effect of human capital accumulation on culture rather than the other way around (see, for example, Fernández and Fogli, 2006). However, to strengthen the evidence, I re-estimate my baseline empirical model (Model 3) using either an alternative culture measure or an alternative sample.

As described in detail in the previous section, the alternative culture measure is a measure of average human capital accumulation in the origin country that is based on data for older individuals. Using older individuals has the advantage of rendering a measure that is even more independent from any confounding influences associated with current migrants and how they behave in their destination countries than my main measure is. Results (Model 4 in Table 4) are highly similar to earlier results. The main difference with earlier results is that culture's effect is estimated less precisely. However, there is simple explanation for this finding, which is that restricting the sample for measuring country-of-origin culture renders a noisier measure of country-of-origin culture compared to the culture measure that is based on the full ESS data set.

The alternative sample that I consider comprises second-generation migrants rather than current migrants (again see the previous section for details). Results indicate that country-of- 
origin culture continues to affect engagement in human capital accumulation, also for individuals that are children from migrants but are themselves born in the destination country (Model 5 in Table 4). The main difference is that the size of the coefficient for culture is smaller than before. This is as expected, however, as a smaller coefficient is consistent with the influence of countryof-origin culture waning over time.

Addressing possible omitted variable bias. In addition to the possibility of reverse causality, the chief reason why the baseline results might not reflect a causal effect of culture on the propensity towards human capital accumulation is that there is an omitted variable bias. Hence, as my main robustness check, I extend the baseline model (Model 3) to include additional variables that control for outcomes related to the accumulation of human capital. Adding outcomes as controls is a powerful means to control for unobserved factors that could cause spurious correlations. However, as stated, doing so also increases the risk of making a Type II error. Noting that models that include outcomes related to the accumulation of human capital as control variables are not my preferred models, I present these results as a particularly prominent and strict check of the robustness of my baseline results.

\section{$<<$ Insert Table 4 about here $>>$}

The first of these strict checks is to take into account unobserved individual-level traits that might affect human capital accumulation, using the amount of schooling that individuals have had, their income and their ability to borrow money as additional control variables. Estimates confirm earlier results, indicating a strong and statistically significant relationship between country-of-origin culture and human capital accumulation (Model 6 in Table 4). 
As the second of these checks, I control for the education level of an individual's father and mother and for the mean years of schooling in the country of origin, which captures the net effect of all the non-cultural features of a country of origin that affect the propensity towards human capital accumulation in this country. Again, results are robust to inclusion of additional control variables (Model 7 in Table 4). Hence, I conclude that there is robust evidence for a cultural gradient in the propensity towards human capital accumulation.

\subsection{Extensions}

Linking culture to human capital accumulation via individual-level dispositions. As the main extension to the baseline results, Table 5 reports results of tests of a possible micro channel through which country-of-origin culture affects migrants' accumulation of human capital in their destination countries. Using mediation analysis, it is possible to assess the extent to which culture has a direct effect on human capital accumulation or an indirect effect that runs through individuals' dispositions, specifically their personal values. Models 8-10 are the main models where the coefficient for country-of-origin culture decreases when the variable measuring individuals' openness-to-change versus conservation values is included (Model 8 versus Model 10). Together, the results imply that about $13.6 \%$ (95\%CI: $10.5 \%-19.0 \%$ ) of the total effect of culture on human capital accumulation is due to culture's effect on individuals' personal values. Hence, there is statistically significant evidence of individuals' values acting as a channel through which culture affects the accumulation of human capital. On the other hand, the size of the mediating effect of personal values is probably not as strong as would be expected when culture would affect human capital accumulation only by affecting individuals' preferences. The evidence presented in Models 8-10 therefore serves to highlight the need to take a combined 
micro/macro approach to complete our understanding of culture's economic consequences. Particularly in an epidemiological setting, macro-level correlations between average tendencies in the country of origin and migrant behavior are best seen as a starting point for further analysis rather than an end point.

\section{$<<$ Insert Table 5 about here $>>$}

Meanwhile, to add to the above evidence on mediation of the culture-behavior relationship, I have also considered a possible mediating effect of individuals' chosen occupation. Results (Models 11-13 in Table 5) confirm that occupation can act as a further channel linking culture to human capital accumulation through individual-level dispositions. Average annual training in an occupation not only has a strong effect on human capital accumulation (Model 11), but controlling for occupational differences also significantly lowers the coefficient for country-oforigin culture (Model 11 versus Model 13). Specifically, the results imply that about $50.1 \%$ (95\%CI: $40.1 \%-67.1 \%$ ) of the total effect of country-of-origin culture on human capital accumulation is mediated by occupation. As before, it seems that we can learn more about the cultural gradient in macroeconomic outcomes if we move beyond aggregate-level epidemiological relationships and consider some specific micro-level features of this gradient.

Intellectual autonomy and future orientation as cultural roots of human capital accumulation. As a second extension, I have re-estimated the main models estimated above, but measuring culture using two specific dimensions of national culture developed by cross-cultural researchers. Out of the many frameworks and dimensions available in the culture measurement literature, I deemed intellectual autonomy and future orientation to be most relevant for understanding 
cultural differences in human capital accumulation. Results indicate that both cultural emphasis on intellectual autonomy (Table 6) and future orientation (Table 7) correlate positively with the propensity towards human capital accumulation. Hence, results confirm the hypothesized positive effects of intellectual autonomy and future orientation on human capital accumulation. In addition, results confirm earlier findings on the mediating effects of personal values and occupation. The found mediating effects for intellectual autonomy are $12.6 \%$ (95\%CI: $10.3 \%$ $16.3 \%$ ) when considering openness-to-change versus conservation values as mediator and $47.5 \%$ (95\%CI: $38.9 \%-61.3 \%$ ) when considering occupation as mediator. The found mediating effects for future orientation are $18.8 \%$ (95\%CI: $13.2 \%-31.0 \%$ ) when considering openness-to-change versus conservation values as mediator and 56.7\% (95\%CI: 40.5\%-91.3\%) when considering occupation as mediator. The main difference with earlier results is that the size of the estimated coefficient for culture can be lower. However, this is easily explained by the fact that the intellectual autonomy and future orientation dimensions have a much broader scope than a culture measure based on a propensity towards one specific behavior has. Hence, the evidence strongly indicates that cross-country differences in human capital accumulation can be traced back to how countries score on the intellectual autonomy and future orientation dimensions of national culture.

$<<$ Insert Tables 6 and 7 about here $>$

Importantly, the results for intellectual autonomy and future orientation as cultural roots of human capital accumulation also increase the plausibility of the causal interpretation of the relationship between national culture and human capital accumulation. The measure of future 
orientation, in particular, is based on data collected between 1995 and 1998 so that scores on this measure cannot have been affected by social, economic or institutional conditions that reigned during the period of collecting the ESS data on migrants' human capital accumulation.

\section{Discussion and conclusion}

A large literature has studied human capital accumulation, particularly as a factor explaining countries' differential growth experiences. Contributing to this literature, I have studied human capital accumulation as a proximate causal growth factor, i.e., as a factor that itself requires explanation. Increasingly, economists are identifying culture as a key informal institution that can explain differences in a variety of phenomena and macroeconomic outcomes. Combining this literature with standard human capital theory's preference-based account of differences in human capital accumulation, I posited that national culture affects individuals' propensity towards human capital accumulation. Following the standard set by recent culture research in economics, for testing this hypothesis, I used an epidemiological approach involving migrants. Empirical results provided strong support for the existence of a cultural gradient in human capital accumulation and this evidence was robust to a variety of checks, including controlling for certain outcome variables associated with the accumulation of human capital such as mean years of schooling in the country of origin.

Following earlier epidemiological culture research, I take this gradient to suggest a cultural explanation for cross-country differences in human capital accumulation. However, to strengthen the analysis, I have also gone beyond broad-level correlations between country-of-origin culture and destination-country behavior to flesh out a possible micro-level channel underlying these correlations. The specific channel that I considered involves a mediating effect of individuals' 
dispositions, which is to say that part of culture's effect on human capital accumulation runs through culture's effect on personal dispositions. I found significant evidence supporting such a micro channel. However, the size of the found mediating effects seems comparatively small. Hence, more research is needed that provides explicit microeconomic underpinning for the typical aggregate-level correlations uncovered by epidemiological culture research.

The final element of the analysis presented in this paper was to unpack the relationship between average behavioral tendencies in the country of origin and migrants' human capital accumulation by considering established dimensions of national culture that would affect this behavior. Empirical results confirmed that two specific dimensions on which cultures are different help explain cross-country differences in the propensity towards human capital accumulation. These two dimensions are countries' cultural emphasis on intellectual autonomy and their future orientation, both of which had a significant positive relationship with migrants' propensity towards human capital accumulation.

Implications of these findings for policy are not immediately obvious. In particular, though perhaps tempting, large-scale and top-down cultural change does not appear very feasible and many would question attempts to do so on normative grounds. However, this paper's findings would alert policy makers to preferences as a potentially important barrier keeping people from accumulating more human capital. Of course, many governments have already deemed human capital accumulation to be sufficiently important to warrant subsidizing education. Still, knowing that a country faces a cultural barrier might induce further policies aimed at making the accumulation of human capital more attractive to citizens.

To conclude, two limitations of the analysis presented in this paper should be noted, the general robustness of the empirical evidence notwithstanding. First, as just indicated, the 
evidence on micro-level channels through which culture goes on to affect the propensity towards human capital accumulation is only partially complete. Of course, this is a generic concern in the epidemiological culture literature. However, it is good to state explicitly that more work is needed to complete our knowledge of culture explaining differences in human capital accumulation (or other economic phenomena for that matter). Second, due to data availability, my sample comprised relatively few countries, maximum 52. In addition, in my sample European countries were overrepresented. The specific properties of my sample have most likely biased my analysis against finding evidence for a cultural gradient in human capital accumulation. Again, however, follow-up research would be needed to generalize my results and further increase our understanding of the role of culture in explaining differences in human capital accumulation. Overall, an important conceptual contribution of this paper is to underscore the need for more work that takes a combined micro/macro approach to study culture as a key factor shaping economic outcomes.

\section{Appendix}

$<<$ Insert Tables A.1-A.2 here>>

\section{References}

Acemoglu, Daron, Simon Johnson, and James A. Robinson. 2001. The Colonial Origins of Comparative Development: An Empirical Investigation. American Economic Review 91 (5), $1369-401$. 
Algan, Yann, and Pierre Cahuc. 2010. Inherited Trust and Growth. American Economic Review $100(5), 2060-92$.

Ashkanasy, Neal M., Vipin Gupta, Melinda S. Mayfield, and Edwin Trevor-Roberts. 2004. Future orientation. In: House, Robert J., Paul J. Hanges, Mansour Javidan, Peter W. Dorfman, and Vipin Gupta, Eds. Culture, Leadership and Organizations: The GLOBE Study of 62 Societies. Thousand Oaks, CA: Sage, 282-342.

Atkin, David. 2016. The caloric costs of culture: Evidence from Indian migrants. American Economic Review 106 (4), 1144-81.

Banfield, Edward C. 1958. The Moral Basis of a Backward Society. New York: Free Press.

Barro, Robert J. 1991. Economic Growth in a Cross-Section of Countries. Quarterly Journal of Economics 106 (2), 407-43.

Becker, Gary. 1964. Human Capital. Chicago: University of Chicago Press.

Bisin, Alberto, Eleonora Patacchini, Thierry Verdier, and Yves Zenou. 2011. Ethnic identity and labour market outcomes of immigrants in Europe. Economic Policy 26 (65), 57-92.

Bisin, Alberto, and Thierry Verdier. 2001. The economics of cultural transmission and the dynamics of preferences. Journal of Economic Theory 97 (2), 298-319.

Cadena, Brian C., and Benjamin J. Keys. 2015. Human capital and the lifetime costs of impatience. American Economic Journal: Economic Policy 7 (3), 126-53.

Carroll, Christopher D., Byung-Kun Rhee, and Changyong Rhee. 1994. Are There Cultural Effects on Saving? Some Cross-Sectional Evidence. Quarterly Journal of Economics 109 (3), 685-99.

Cordoba, Juan Carlos, and Marla Ripoll. 2013. What Explains Schooling Differences across Countries? Journal of Monetary Economics 60 (2), 184-202. 
Cortazzi, Martin, and Lixian Jin, Eds. 2013. Researching Cultures of Learning: International perspectives on language learning and education. Houndmills: Palgrave, Macmillan.

Davis, Lewis S., and Farangis Abdurazokzoda. 2016. Language, culture and institutions: Evidence from a new linguistic dataset. Journal of Comparative Economics 44 (3), 541-61.

Davis, Lewis S., and Claudia Williamson. 2016. Culture and the Regulation of Entry. Journal of Comparative Economics 44 (4), 1055-83.

Erosa, Andres, Tatyana Koreshkova, and Diego Restuccia. 2010. How Important Is Human Capital? A Quantitative Theory Assessment of World Income Inequality. Review of Economic Studies 77 (4), 1421-49.

European Social Survey. 2014. Cumulative File, ESS 1-6. Data file edition 1.1. Norwegian Social Science Data Services, Norway - Data Archive and distributor of ESS data.

Fernández, Raquel, and Alessandra Fogli. 2006. Fertility: The role of culture and family experience. Journal of the European Economic Association 4 (2-3), 552-61.

Fukuyama, Francis. 1995. Trust: The social virtues and the creation of prosperity. New York: Free press.

Gennaioli, Nicola, Rafael LaPorta, Florencio Lopez-de-Silanes, and Andrei Shleifer. 2013. Human Capital and Regional Development. Quarterly Journal of Economics 128 (1), 105-64.

Glaeser, Edward L., Rafael La Porta, Florencio Lopez-de-Silanes, and Andrei Shleifer. 2004. Do Institutions Cause Growth? Journal of Economic Growth 9 (3), 271-303.

Gorodnichenko, Yuriy, and Gérard Roland. 2011. Which Dimensions of Culture Matter for Long Run Growth? American Economic Review 101 (3), 492-8.

Gorodnichenko, Yuriy, and Gérard Roland. 2016. Culture, institutions and the wealth of nations. Review of Economics and Statistics, In press. 
Grosfeld, Irena, and Ekaterina Zhuravskaya. 2015. Cultural vs. economic legacies of empires: Evidence from the partition of Poland. Journal of Comparative Economics 43 (1), 55-75.

Guiso, Luigi, Paola Sapienza, and Luigi Zingales. 2006. Does culture affect economic outcomes? Journal of Economic Perspectives 20 (2), 23-48.

Hofstede, Geert. 1980. Culture's Consequences: International Differences in Work-Related Values. Beverly Hills, CA: Sage.

Hofstede, Geert. 2001. Culture's consequences: comparing values, behaviors, institutions, and organizations across nations. Thousand Oaks, CA: Sage.

Hofstede, Geert, and Michael Minkov. 2010. Long-versus short-term orientation: new perspectives. Asia Pacific Business Review 16 (4), 493-504.

House, Robert J., Paul J. Hanges, Mansour Javidan, Peter W. Dorfman, and Vipin Gupta, Eds. 2004. Culture, Leadership, and Organizations: The GLOBE Study of 62 Societies. Thousand Oaks, CA: Sage.

Javidan, Mansour, Robert J. House, Peter W. Dorfman, Paul J. Hanges, and Mary Sully de Luque. 2006. Conceptualizing and measuring cultures and their consequences: A comparative review of GLOBE's and Hofstede's approaches. Journal of international Business Studies 37 (6), 897-914.

Klasing, Mariko J. 2013. Cultural dimensions, collective values and their importance for institutions. Journal of Comparative Economics 41 (2), 447-67.

Knack, Stephen, and Philip Keefer. 1997. Does social capital have an economic payoff? A crosscountry investigation. Quarterly Journal of Economics 112 (4), 1251-88.

Knafo, Ariel, and Lilach Sagiv. 2004. Values and work environment: Mapping 32 occupations. European Journal of Psychology of Education 19 (3), 255-73. 
Landes, David S. 1998. The wealth and poverty of nations: why some countries are so rich and some so poor. New York: W.W. Norton.

Lucas, Robert E. Jr. 1993. Making a Miracle. Econometrica 61 (2), 251-72.

Mankiw, N Gregory, David Romer, and David N. Weil. 1992. A Contribution to the Empirics of Economic Growth. Quarterly Journal of Economics 107 (2), 407-37.

Manuelli, Rodolfo E., and Ananth Seshadri. 2014. Human capital and the wealth of nations. American Economic Review 104 (9), 2736-62.

Maseland, Robbert, and André Van Hoorn. 2009. Explaining the negative correlation between values and practices: A note on the Hofstede-GLOBE debate. Journal of International Business Studies 40 (3), 527-32.

Maseland, Robbert, and André Van Hoorn. 2010. Values and marginal preferences in international business. Journal of International Business Studies 41 (8), 1325-9.

Maseland, Robbert, and André Van Hoorn. 2016. Culture at the Country Level. In: Van Herk, Hester, and Carlos J. Torelli, Eds. Cross-Cultural Issues in Consumer Science and International Business. Berlin: Springer, In press.

Mayer, Thierry, and Soledad Zignago. 2011. Notes on CEPII's distances measures: The GeoDist database. Working Papers 2011-25, CEPII research center.

Mincer, Jacob. 1958. Investment in Human Capital and Personal Income Distribution. Journal of Political Economy 66 (4), 281-302.

Minkov, Michael. 2007. What makes us different and similar: A new interpretation of the World Values Survey and other cross-cultural data. Sofia: Klasika i Stil Publishing House.

North, Douglass C., and Robert Paul Thomas. 1973. The rise of the western world: A new economic history. Cambridge, UK: Cambridge University Press. 
Nunn, Nathan. 2012. Culture and the Historical Process. Economic History of Developing Regions 27 (S1), 108-26.

Oster, Emily, Ira Shoulson, and E. Ray Dorsey. 2013. Limited Life Expectancy, Human Capital and Health Investments. American Economic Review 103 (5), 1977-2002.

Roland, Gérard. 2015. Economics and Culture. Emerging Trends in the Social and Behavioral Sciences: An Interdisciplinary, Searchable, and Linkable Resource.

Schwartz, Shalom H. 1992. Universals in the content and structure of values: Theoretical advances and empirical tests in 20 countries. Advances in Experimental Social Psychology 25: $1-65$.

Schwartz, Shalom H. 1994. Beyond individualism/collectivism: New cultural dimensions of values. In Kim, Uichol, Harry C. Triandis, Cigdem Kagitcibasi, Sang-Chin Choi, and Gene Yoon, Eds. Individualism and Collectivism: Theory, Methods and Applications. London: Sage, 85-119.

Schwartz, Shalom H. 2006. A theory of cultural value orientations: Explication and applications. Comparative Sociology 5 (2/3), 137-82.

Schwartz, Shalom H., Gila Melech, Arielle Lehmann, Steven Burgess, Mari Harris, and Vicki Owens. 2001. Extending the cross-cultural validity of the theory of basic human values with a different method of measurement. Journal of Cross-Cultural Psychology 32 (5), 519-42.

Spolaore, Enrico, and Roman Wacziarg. 2013. How Deep Are the Roots of Economic Development? Journal of Economic Literature 51 (2), 325-69.

Stackman, Richard W., Patrick E. Connor, and Boris W. Becker. 2006. Sectoral ethos: An investigation of the personal values systems of female and male managers in the public and private sectors. Journal of Public Administration Research and Theory 16 (4), 577-97. 
Taras, Vas, Piers Steel, and Bradley L. Kirkman. 2010. Negative practice-value correlations in the GLOBE data: Unexpected findings, questionnaire limitations and research directions. Journal of International Business Studies 41 (8), 1330-8.

UNDP. 2016. Human Development Data (1980-2015), Mean years of schooling (of adults) (years). http://hdr.undp.org/en/data\#.

Van Hoorn, André. 2014. Individualism and the cultural roots of management practices. Journal of Economic Behavior \& Organization 99, 53-68.

Van Hoorn, André. 2015. The global financial crisis and the values of professionals in finance: An empirical analysis. Journal of Business Ethics 130 (2), 253-69.

Voigtländer, Nico, and Hans-Joachim Voth. 2012. Persecution perpetuated: the medieval origins of anti-Semitic violence in Nazi Germany. Quarterly Journal of Economics 127 (3), 1339-92.

Weber, Max. 1904/5. The Protestant Ethic and the Spirit of Capitalism. Translated by Talcott Parsons. London / New York: Routledge [1930]. 